\title{
Modelling Windage Power Loss from an Enclosed Spur Gear
}

\author{
$\mathrm{K}$ Al-Shibl \\ School of Mechanical, Materials and \\ Manufacturing Engineering, \\ University of Nottingham, University \\ Park, Nottingham, NG7 2RD, UK \\ +441159513800 \\ eaxka@nottingham.ac.uk \\ JPE344
}

\author{
K Simmons \\ School of Mechanical, Materials and \\ Manufacturing Engineering, \\ University of Nottingham, University \\ Park, Nottingham, NG7 2RD, UK \\ +441159513728 \\ +441159513800 \\ kathy.simmons@nottingham.ac.uk
}

\author{
C N Eastwick \\ School of Mechanical, Materials and \\ Manufacturing Engineering, \\ University of Nottingham, University \\ Park, Nottingham, NG7 2RD, UK \\ +441159513788 \\ +441159513800 \\ carol.eastwick@nottingham.ac.uk
}

\begin{abstract}
Within a gearbox the majority of transmission losses can be attributed to bearing losses, meshing losses or losses due to windage/churning. In this paper the commercial CFD code Fluent 6.2.16 is applied in a 2D study of windage power loss (WPL) from a single spur gear rotating in air. By comparing CFD data to published experimental data appropriate grid density and modelling parameters are identified. The model is used to investigate how peripheral shrouding affects WPL and whether WPL can be reduced through minor modifications to tooth tip geometry.
\end{abstract}

Non-dimensional shroud spacings (ratio of gap to gear PCD) of between 0.005 and 0.05 were investigated at shaft speeds between 5,000 rpm and 20,000 rpm. Although CFD data compared reasonably well to experimental data, trends were not reproduced and an optimum shroud could not be identified. A full 3D study is recommended.

Modifying the tooth tip by adding a small chamfer on the leading edge reduced WPL by approximately $6 \%$. A small fillet increased total WPL by a similar amount suggesting that WPL may increase as a gear wears. This preliminary study suggests further work in this area would be beneficial.

Keywords. Spur gear, power loss, windage, computational, modelling, CFD 


\section{Background}

\subsection{Introduction}

Within a gearbox there are losses in power transmission and the majority of these can be attributed to one of three causes, bearing losses, meshing losses and losses due to windage/churning. In the best case, for high power applications gearbox efficiencies of up to 99\% can be obtained with the highest rated gearboxes now exceeding 100MW [1]. For such a gearbox a $1 \%$ power loss equates to $1 \mathrm{MW}$ and this is not insignificant. Of the total losses, for a typical gearbox, $40 \%$ come from meshing, 50\% from bearings and $10 \%$ from windage and churning [2]. In this study work has focussed on windage power loss (WPL) for a single spur gear rotating in air. The work has two aims, firstly to develop an approach to predicting WPL and secondly to apply those methods to minimise WPL for the gear geometry studied.

In order to rotate a gear in a fluid work must be done to overcome the resistance/drag of the fluid over the gear. Energy is transferred to the fluid and for a single (unmeshed) gear this energy transfer can be identified as the power absorbed by the gear above the power required to operate the system without the gear in place. Typically, windage losses are defined as those due to the presence of oil/air mist around the gear and churning losses occur when the gear dips into a pool or film of liquid oil or rotates through slugs of oil. WPL will always be present whereas churning often does not occur at all.

The ability to predict the losses associated with rotating gears is important in the design stage of many industrial, marine and aeroengine applications. Whilst equations are available to predict the windage power loss of gears, all are based on experimental correlations [2-13] and are restricted in application in many cases. This means that designers have, at best, an estimate of the WPL and in addition, cannot take their design too far from previous, successful designs, thus limiting the design envelope. Computational Fluid Dynamics (CFD) has the potential to create accurate models of gear geometries and thus give designers an approach to predicting WPL with greater accuracy and for configurations not covered by available correlations. However, a full 3D, multiphase model of oil lubricated, meshing gears would be 
extremely computationally expensive and should be approached in a series of sensible, validated steps. This study applies Computational Fluid Dynamics (CFD) to the flow around a single spur gear rotating in air as there is good experimental data available for comparison. The results presented here are for a 2D model, 3D modelling work will follow.

In addition to predicting WPL, a design aim would be to reduce losses. Although $10 \%$ of the total losses may seem a small proportion, nevertheless, as other parts of the gearbox become more efficient the windage power loss component becomes more significant. Traditionally there have been two approaches to reducing windage losses, the first is to use a shroud or baffle to enclose the gears and the second is to pump the oil and air from the gearbox casing. Weiss \& Hirt [1] investigated gearbox evacuation as a means of reducing the effective fluid density within the casing. They found an improvement in efficiency of up to a $1 \%$ but evacuation can only be used in a limited number of situations. Shrouding is a far more promising approach that is already widely used within industry. A number of authors have investigated shrouding for either spur or helical gears [2-13] and this study builds on previous work, investigating the effects of shrouding and tooth form modification. CFD data is compared with published experimental data where possible.

\subsection{Previous work}

Previous experimental research on gear windage power loss has established that gear shrouding can have a significant impact in reducing WPL. Lord [2] investigated WPL for spur and bevel gears at shaft speeds up to $20,000 \mathrm{rpm}$, reporting a wealth of data on single and meshing gears for a number of shroud configurations. For the spur gear studied (PCD 200mm, module $1 \mathrm{~mm}$ and face width $40 \mathrm{~mm}$ ) shrouding an unmeshed gear leads to up to $25 \%$ reduction in WPL compared to a free rotating case. Lord found that for the configurations studied WPL increases linearly with increasing peripheral shroud clearance. In contrast, for the bevel gear studied an optimum peripheral radial clearance was identified at which the WPL is a

minimum. Lord found the most significant factors influencing WPL are the gear radius and rotational speed. As the Lord study is by far the most detailed and comprehensive available, model geometries have been chosen to correspond to those of Lord. 
Dawson $[3,4]$ carried out a number of experimental investigations for single spur and helical gears constructed of hardboard material rotating in air, with partially and totally shrouded configurations. The range of tooth root diameters was from 300 to $1160 \mathrm{~mm}$ and rotational speeds up to $1500 \mathrm{rpm}$ were investigated. A number of shrouding configurations were investigated leading to reductions in WPL ranging between $14 \%$ and $66 \%$. The maximum reduction in WPL was obtained for a smooth shroud totally enclosing the gear with $15 \mathrm{~mm}$ peripheral shroud clearance and $27 \mathrm{~mm}$ axial shroud clearance. The effect of shroud surface finish was studied for one shroud configuration totally enclosing the gear by comparing a rough surface finish with a smooth one. The smooth finish gave an improvement of $34 \%$ compared to the rough finish. It was possible to fit a power relationship linking WPL to rotational speed and this is one of the empirical expressions currently employed by the design community.

Diab et al [12] presented an experimental study of a single spur gear rotating in air without enclosure. Four spur gears were investigated, with pitch diameters from $144-300 \mathrm{~mm}$, face width $30-60 \mathrm{~mm}$ and modules of 4 and 6 . Two expressions were derived for windage power loss, one from dimensional analysis and the second based on addition of power loss from the sides of the gear and teeth, which were informed correlations from the experimental data. Flanges were used to block the axial inlet and outlet to the teeth for a single gear of module 6 and a reduction of $60 \%$ in WPL was seen, which is considerably larger than most of the values seen in Dawson's work. A follow on paper [13] has extended this work to include a helical gear as well and looked at introducing an oil mist into an enclosure around the gear. The conclusion of the paper was that the oil mist did not change the windage power loss but the paper does not record the level of oil introduced nor the method of introduction (beyond a mist) or degree of enclosure all of which would have affected the behaviour of the oil within the enclosure and hence its degree of impact on the power loss.

Another factor found to significantly affect WPL is the gear tooth tip geometry as this influences the flow near the front side of the exposed surface affecting flow separation and the generation of turbulent vortices. Modifying the standard sharp tip with a small chamfer or fillet leads to improved material handling and extended wear life and was found by Dawson [3] to 
reduce WPL. In his experimental study, Dawson [3] investigated WPL from a spur gear with a $5^{\circ}$ chamfer on half tooth tip and found that the WPL was reduced by $15 \%$ compared to the unchamfered case.

\section{Methodology}

In this paper single phase flow around a single spur gear is investigated using the commercial CFD code Fluent 6.2.16. The effect of shrouding parameters are evaluated and compared with the data of Lord [2]. In addition the effect of modifying the tooth tip geometry is investigated and the results compared to those of Dawson [3]. In this section the geometry, mesh, boundary conditions, turbulence and wall model together with general model features are given.

\subsection{Geometry}

A two dimensional spur gear model with the same geometric parameters as that investigated by Lord [2] was constructed in AutoCAD (2002). The characteristics of the spur gear modelled are a module of $1 \mathrm{~mm}$, pressure angle of 20 degrees, pitch circle diameter of $200 \mathrm{~mm}$ and a face width $40 \mathrm{~mm}$. Figure 1 shows the modelling domain, a $3.6^{\circ}$ sector of the spur gear comprising two teeth. The two dimensional model calculates the flow over the teeth assuming they are of infinite thickness, so the sides of the gear are not modelled. The windage power loss predicted therefore does not include side losses. Section 2.4 describes how these were taken into account.

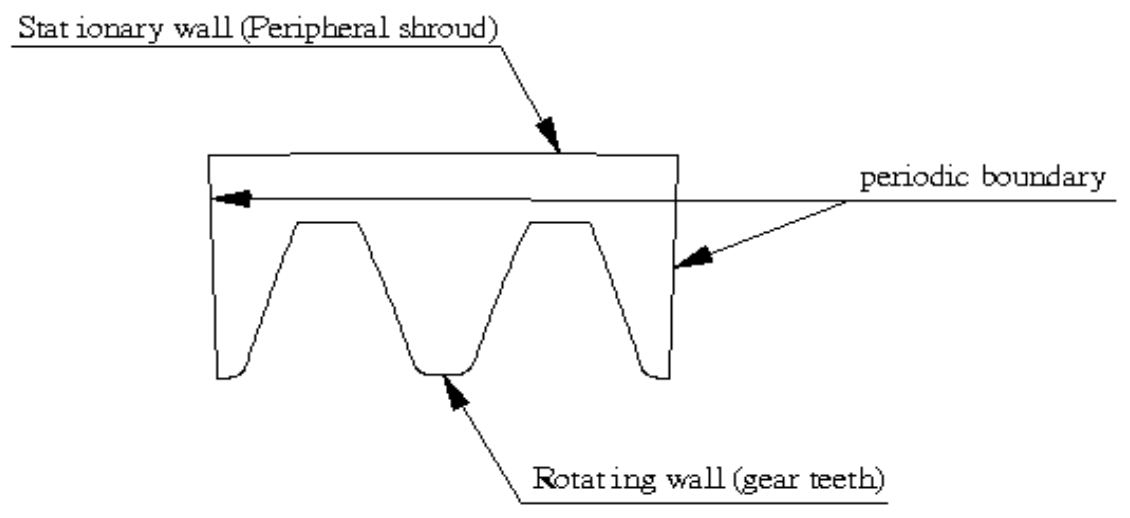

Figure 1: Physical domain modelled showing boundary conditions 
The distance between the gear teeth and the peripheral shroud is a variable in the models as peripheral shroud spacing is the primary variable being investigated. The relevant parts of the Lord test rig [2] together with significant dimensions are shown in Figure 2.
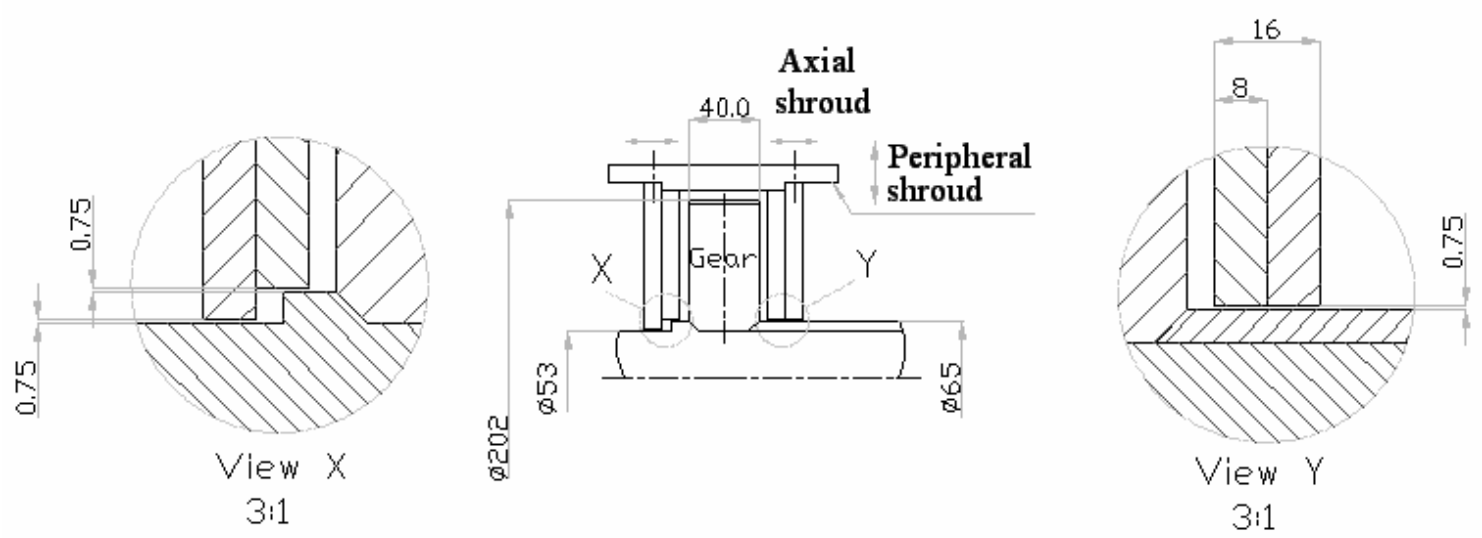

Figure 2: Illustration of Lord test rig [2] (dimensions in $\mathrm{mm}$ ).

\subsection{Mesh}

The geometry created in AUTOCAD was imported to Gambit (Fluent's pre-processor) and meshed using a body-fitted mesh of triangular cells. Cell size distribution was controlled using a size function and an appropriate near-wall cell size was determined from a preliminary study (see Section 2.3).

An extensive grid independence study was undertaken and optimum meshes were identified for each of the rotation speeds. A typical computational mesh is shown in Figure 3 where it can be seen that the mesh is very dense close to the walls and between the gear teeth (for example, the near wall cells on the gear have $\mathrm{y}^{+}$values in the range 0.5 to 3.5 and sizes between $20 \mu \mathrm{m}$ and $80 \mu \mathrm{m}$ ). The illustrated mesh has 26,216 cells for a peripheral shroud clearance of $5 \mathrm{~mm}$ and was for a shaft speed of 20,000 rpm. 


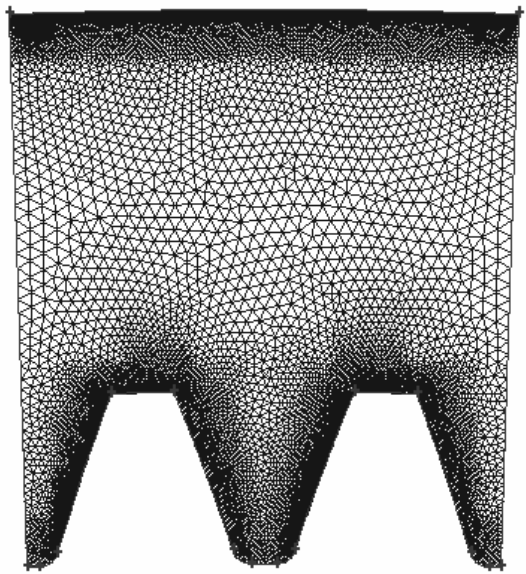

Figure 3: Typical mesh (5 $\mathrm{mm}$ peripheral shroud spacing shown).

\subsection{Model Details}

The model outline and associated boundary conditions are illustrated in Figure 1 . As the geometry (and anticipated flow solution) has a periodically repeating nature, a rotationally periodic boundary condition is applied to the radial edges bounding the domain. In this the flow and pressure profiles along left and right hand radial boundaries are constrained to be identical.

The flow is modelled as steady state and to account for the moving gear and stationary shroud a rotating reference frame centred on the gear axis is used. The rotating gear is modelled as a no-slip wall moving with zero angular velocity relative to the rotating reference frame. The outer boundary (shroud wall or free air) is modelled as a stationary no-slip wall with absolute zero angular velocity. Within Fluent the governing equations are appropriately modified when a rotating reference frame is used.

Using the rotating Reynolds number $\mathrm{Re}_{\text {rot, }}$ the Reynolds number range of the Lord data (rotational speeds between 5000 and $20,000 \mathrm{rpm}$ ) is $3.6 \times 10^{5}$ to $1.4 \times 10^{6}$. For the spur gear Lord reported transition from laminar to turbulent flow at Reynolds numbers between $9 \times 10^{4}$ and $2 \times 10^{5}$ and consequently in the CFD model the flow is modelled as turbulent. Following Lee [14] it was felt that the Reynolds Stress Model would be the most accurate turbulence model for these configurations. In order to verify this, a comprehensive study was undertaken comparing CFD data computed using the standard $k-\varepsilon$ (Launder \& Spalding [15]), RNG $k-\varepsilon$ 
(Choudhury [16]) and Reynolds stress (RSM) (Launder et al [17]) turbulence models in Fluent to experimental data. As the experimental data included both side and peripheral losses whereas the 2D CFD data includes only peripheral losses a correlation (see section 2.7) was used to give the side losses. Where the peripheral shroud clearance was $1 \mathrm{~mm}$ all turbulence models performed well but for larger clearances $(5 \mathrm{~mm}$ and $10 \mathrm{~mm}$ ) there was some difference between CFD and experimental data with the RSM model giving data closest to that of Lord. A sample data set is shown in Figure 4 for a $5 \mathrm{~mm}$ peripheral clearance. On the basis of previous work and this study the Reynolds Stress turbulence model was used throughout the study.

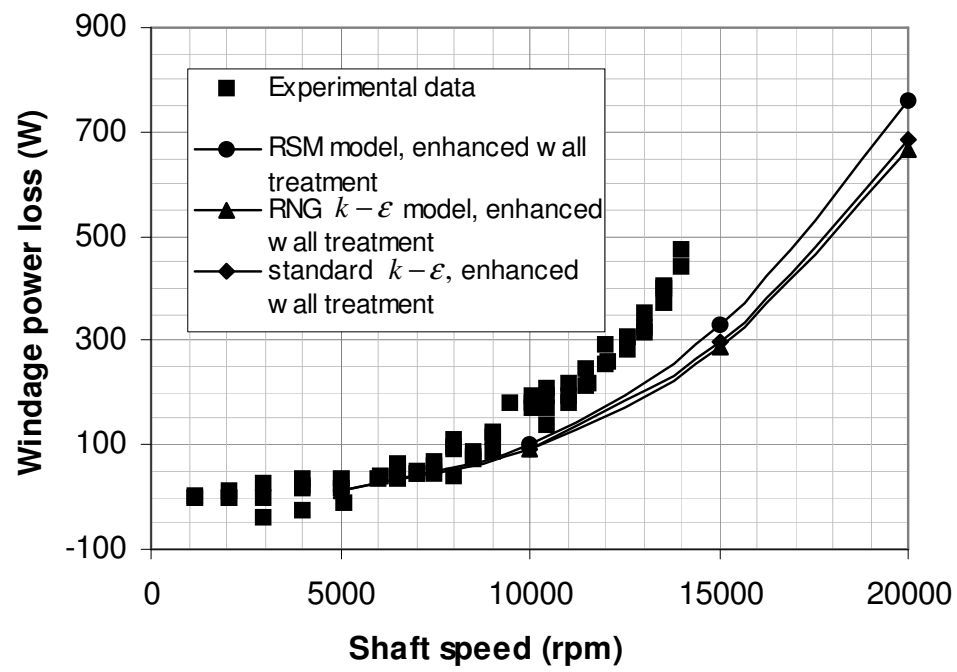

Figure 4: Comparison of computed WPL to experimental data for the $5 \mathrm{~mm}$ radial clearance model.

As the calculated windage power loss is a direct function of the velocity gradient at the wall it is important that wall treatment is appropriate and adequate. If the near-wall mesh is sufficiently fine $\left(y^{+} \sim 1\right)$, then the laminar sublayer can be resolved (two-layer zonal approach) or alternatively for $\mathrm{y}^{+}>11.25$ standard wall functions (Launder and Spalding [15]) can be applied. Fluent's enhanced wall treatment (Kader [18]) blends linear (laminar) and logarithmic (turbulent) laws of the wall and offers a compromise in that near-wall cell sizes can fall within the laminar sublayer and transition regions without adversely affecting the solution. A further advantage of enhanced wall treatment is that is far better suited for flows with severe pressure gradients, boundary layer separation or strong body forces such as in rotating flows. Solutions obtained using both coarser wall meshes (standard wall functions) and fine 
wall meshes (enhanced wall treatment) were investigated for a number of turbulence models. It was concluded that enhanced wall treatment gave the best match to experimental data and should be employed.

The flow is modelled as incompressible, isothermal with constant physical properties (equivalent to atmospheric air at $15^{\circ} \mathrm{C}$ ) and the gravitational force is neglected. The effect of assuming incompressible flow was investigated as the gear surface velocities at higher rotational rates are significant with a Mach number of 0.7 at 20,000 rpm. However modelling the flow as compressible altered the computed windage power loss by only $0.22 \%$ and the pressure contours obtained were almost indistinguishable from those computed on the incompressible model. The differencing scheme employed is the second order upwind interpolation scheme with the pressure correction scheme PRESTO and SIMPLE as pressure velocity coupling algorithm.

For a single gear rotating in air within a shroud, the effect of windage is for the air to heat up. There is heat transfer through the shroud material to the external air and initially a transient condition exists until equilibrium between generated and lost heat is attained. At this equilibrium condition the air temperature within the shroud is constant (indicating constant properties). By modelling the flow as isothermal with constant physical properties, this steady-state condition is mimicked but each WPL would be associated with a different equilibrium temperature. In the experimental work (Lord[2]) data was obtained for different shaft speeds during a test cycle. Reasonably steady conditions would probably have existed at each test point but there was probably not total thermal equilibrium. For air, as temperature increases, viscosity increases and density decreases.

In order to assess the effect of temperature, WPL data was obtained computationally for a single shroud configuration and shaft speed $(20,000 \mathrm{rpm}, 5 \mathrm{~mm}$ peripheral shroud spacing) run isothermally with air properties appropriate to a range of steady-state temperatures within the range $20^{\circ} \mathrm{C}$ to $50^{\circ} \mathrm{C}$. The results are shown in Figure 5; it was found that both the viscous and pressure losses reduced slightly with increasing temperature. Unfortunately, air temperature 
was not recorded in the Lord study but it is unlikely that it would have exceeded $35^{\circ} \mathrm{C}$. At $30^{\circ} \mathrm{C}$ the difference in total WPL to that obtained for $15^{\circ} \mathrm{C}$ is $2 \%$ and $3 \%$ at $40^{\circ} \mathrm{C}$. As the air temperature for each case is not known an arbitary temperature of $15^{\circ} \mathrm{C}$ has been used throughout.

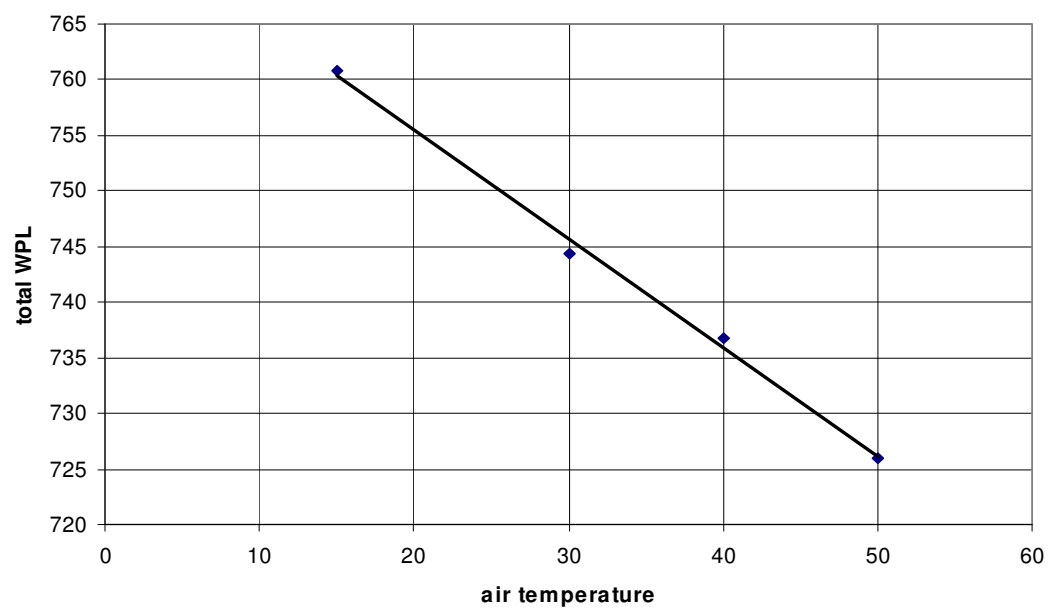

Figure 5: Variation in total computed WPL with air temperature

\subsection{Calculation of Windage Power Loss (WPL)}

The peripheral WPL was calculated from the viscous and pressure moments reported for the computed flow field. The experimental data [2] used for validation includes teeth and sides losses from the gear. In order to allow comparison of the 2D computed model and the experimental data the gear side loss has to be included. This is achieved by use of an expression for the side power loss taken from Townsend [7]. That expression was empirically derived for a blank smooth body rotating in air and can be written as:

$$
P_{\text {sides }}=15,000\left(\frac{N}{1000}\right)^{3}\left(\frac{D}{2.54}\right)^{5}
$$

The side losses from the Townsend correlation are added to the CFD WPL to yield a total value that can be compared directly to experimental data.

\section{Results}

The first section, 3.1, within this results segment establishes the capability of the 2D CFD model to predict WPL with reasonable fidelity. Section 3.2 provides an overview of the flow field results showing both velocity and pressure fields and discussing their significance. In Section 3.3 viscous losses for the gear are compared to viscous losses for an equivalent disk. 
Section 3.4 demonstrates the effect peripheral shroud clearance has on windage power loss, with comparisons between predictions and experimental data shown. The effect of tooth geometry on windage power loss is investigated and described in section 3.5.

\subsection{Prediction capability}

A plot of the variation in total WPL with shaft speed for the $1 \mathrm{~mm}$ peripheral shroud clearance model is shown in Figure 6, where it is compared up to a rotational speed of $20,000 \mathrm{rpm}$ to Lord's [2] experimental data. Similar plots can be obtained for 5mm (Figure 4) and $10 \mathrm{~mm}$ peripheral shroud spacings. Although the CFD differs slightly from the experimental data, trends are well reproduced. The Lord data of Figure 6 contains some negative values and if these are disregarded then a power law curve can be fitted to the data having the equation:

$$
P=1.3306 \times 10^{-10} N^{2.9742}
$$

The CFD data is reasonably close to that of Lord with the negligible difference from the curve fit at $5000 \mathrm{rpm}$ increasing to $14 \%$ at $17,000 \mathrm{rpm}$ (the highest experimental shaft speed for that shroud configuration). It is apparent that the contribution of the side losses is significant and as a correlation is used to obtain the value included in the computed total WPL, this is very dependent on the accuracy and applicability of the correlation chosen. A full three dimensional CFD model would remove that dependence. Nevertheless this 2D model has established the capability of the CFD model to capture essential flow behaviour and as such the model can be used for further analysis.

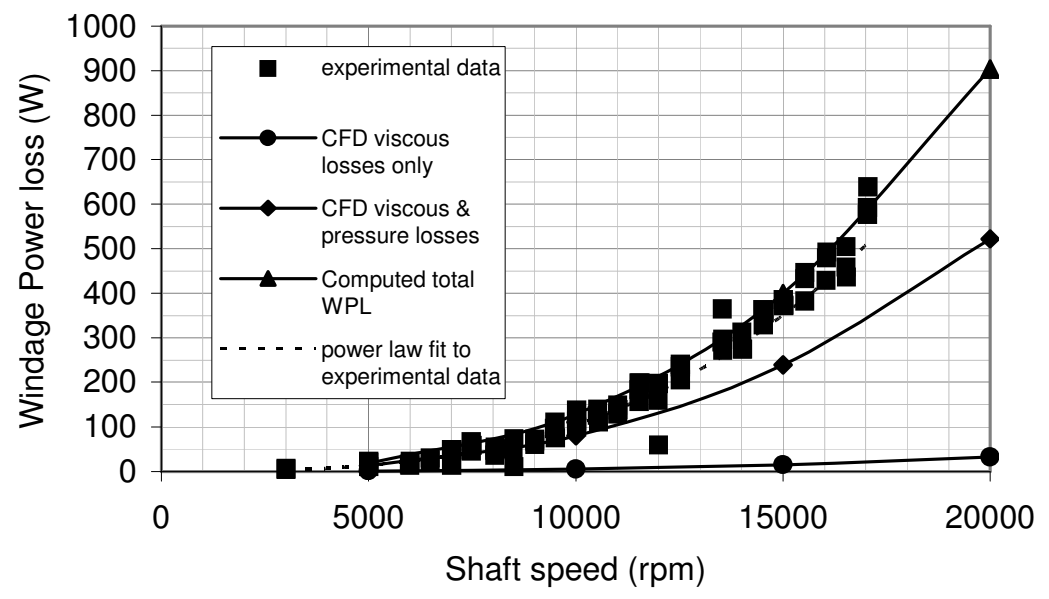

Figure 6: Contribution to total WPL of viscous, pressure and side losses with shaft speed for a peripheral shroud spacing of $1 \mathrm{~mm}$. 


\subsection{Flow field}

Having established that the CFD is capturing WPL with reasonable fidelity, it is now possible to analyse the CFD flow field in greater detail, providing information not available from the experimental study. Figure 7a shows a typical vector plot, in this case for a shaft speed of $20,000 \mathrm{rpm}$ and a peripheral shroud clearance of $1 \mathrm{~mm}$. As illustrated the flow within the tooth cavity primarily rotates with the gear. Fig $7 \mathrm{~b}$ shows the velocity vectors relative to the rotating reference frame and in the tooth cavity this illustrates the way the air moves relative to the gear teeth. As indicated, the magnitude of this "secondary" flow velocity is two to four orders of magnitude lower than the primary velocity. This plot shows clearly that the air within the tooth cavity does not simply rotate as a solid body. Similar plots are obtained for all shaft speeds investigated.

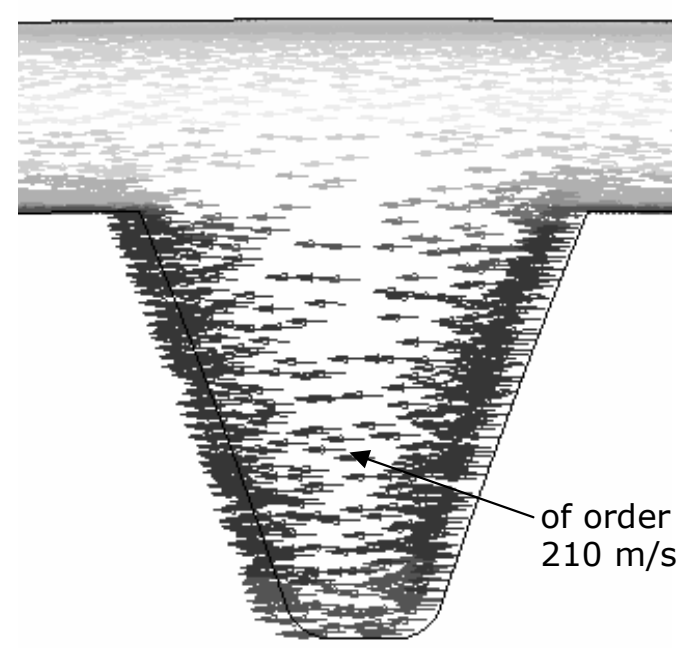

a) Velocity vectors (absolute)

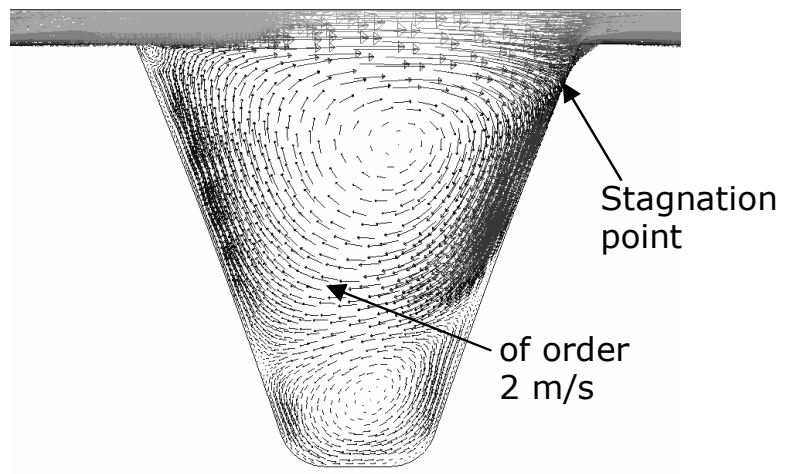

b) Velocity vectors relative to rotating reference frame

Figure 7: Velocity vectors at 20,000 rpm with $1 \mathrm{~mm}$ peripheral shroud spacing.

The stagnation point created by the flow from one tooth impinging on the next is also clear - it is this, as Figure 8 shows, that modifies the standard radial pressure gradient within the tooth cavity such that there is a pressure difference across the tooth. The difference in pressure between the front and back faces of each tooth gives rise to a retarding torque on the gear. The retarding torque from the pressure variation is significantly greater than that arising from viscous losses. At 20,000 rpm with a peripheral shroud spacing of $1 \mathrm{~mm}$ the WPL from viscous effects is calculated to be $33 \mathrm{~W}$ whereas the WPL from pressure effects is $489 \mathrm{~W}$. The contribution to WPL from the gear sides is calculated to be $382 \mathrm{~W}$ using the Townsend [7] 
correlation. Analysis of Figure 8 suggests that minor modifications to the tooth profile could lead to significant reduction in WPL if the pressure concentration highlighted could be reduced and a limited investigation into this is reported in Section 3.5.

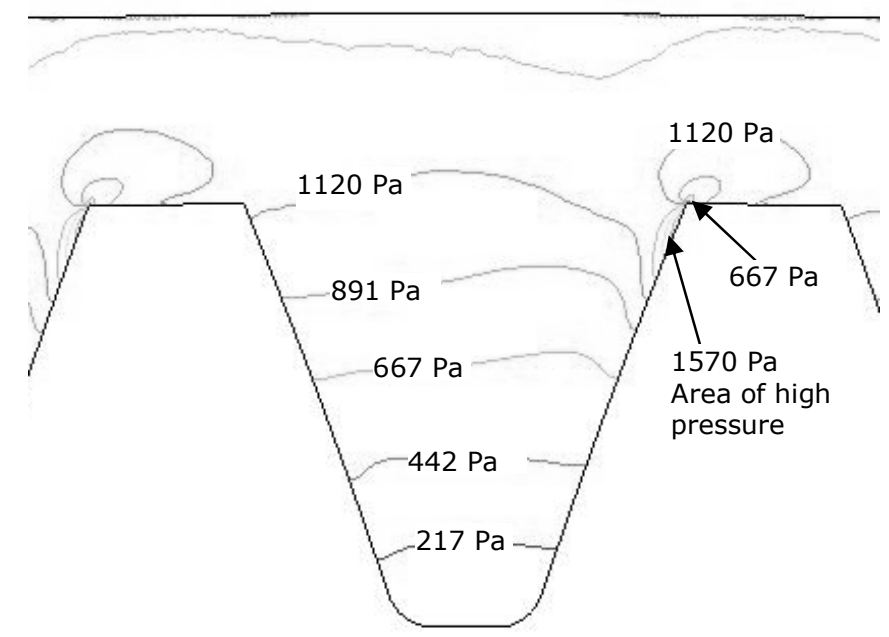

Figure 8: Contours of static pressure for $1 \mathrm{~mm}$ peripheral shroud clearance and 20,000 rpm.

Profiles of azimuthal velocity taken along radial lines at tooth valley/cavity centre and tooth tip centre (illustrated in Figure 9a) are shown in Figure 9b for the case of a $1 \mathrm{~mm}$ peripheral shroud clearance and at a speed of $20,000 \mathrm{rpm}$. In Figure $9 \mathrm{~b}$ the radial distance $r$ has been non-dimensionalised with peripheral shroud spacing yielding $\mathrm{R}^{\prime}$ and the azimuthal velocity, $V^{\prime}$, has been non-dimensionalised with gear tip linear speed. The figure shows clearly that there is very little variation in velocity profile external to the gear between a tooth peak and valley. In addition, the velocity profile between tooth tip and shroud is superficially similar to that for a shrouded disk and this suggested that it might be possible to estimate viscous losses for a gear from the viscous losses for the equivalent disk. This is explored further in Section 3.3

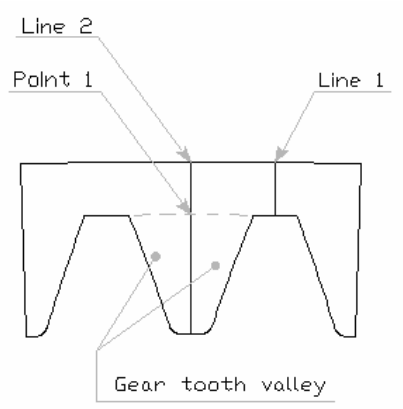

Figure 9a: Schematic showing locations referred to as tooth valley (also called cavity) and tooth tip 


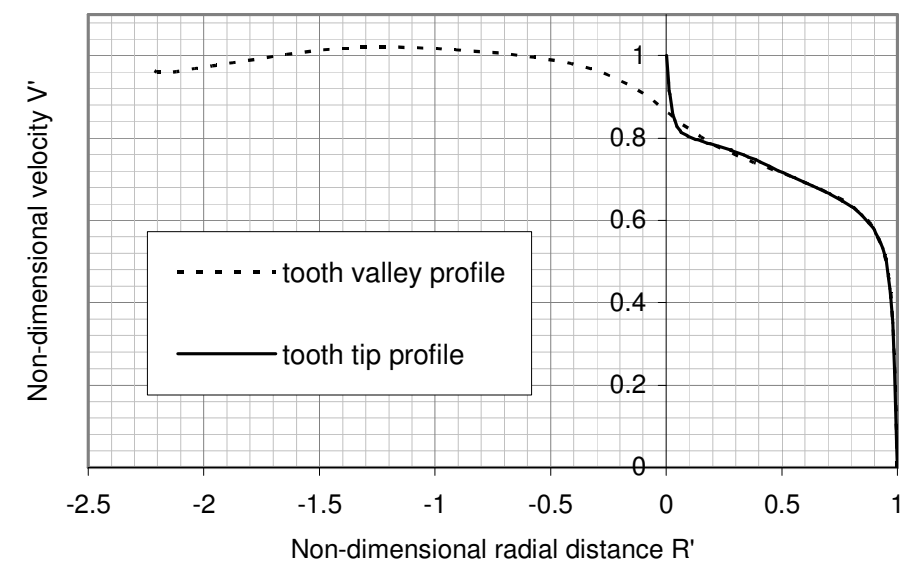

Figure 9b: Azimuthal velocity profiles across the radial gap between gear and shroud at tooth tip and tooth valley.

\subsection{Comparison of the viscous component of WPL for a disk and a gear}

Figure 10 shows the computed velocity profile for a disk of outer diameter $202 \mathrm{~mm}$ with a $1 \mathrm{~mm}$ peripheral shroud clearance. The profile is similar to that for the gear between tooth tip and shroud although the core velocity is significantly higher in the case of the gear and consequently, as the inset shows, the gradient at the surface is steeper for the disk. It is of interest to assess the extent to which is may be possible to predict the viscous losses for the gear by considering an appropriate fraction of the equivalent disk.

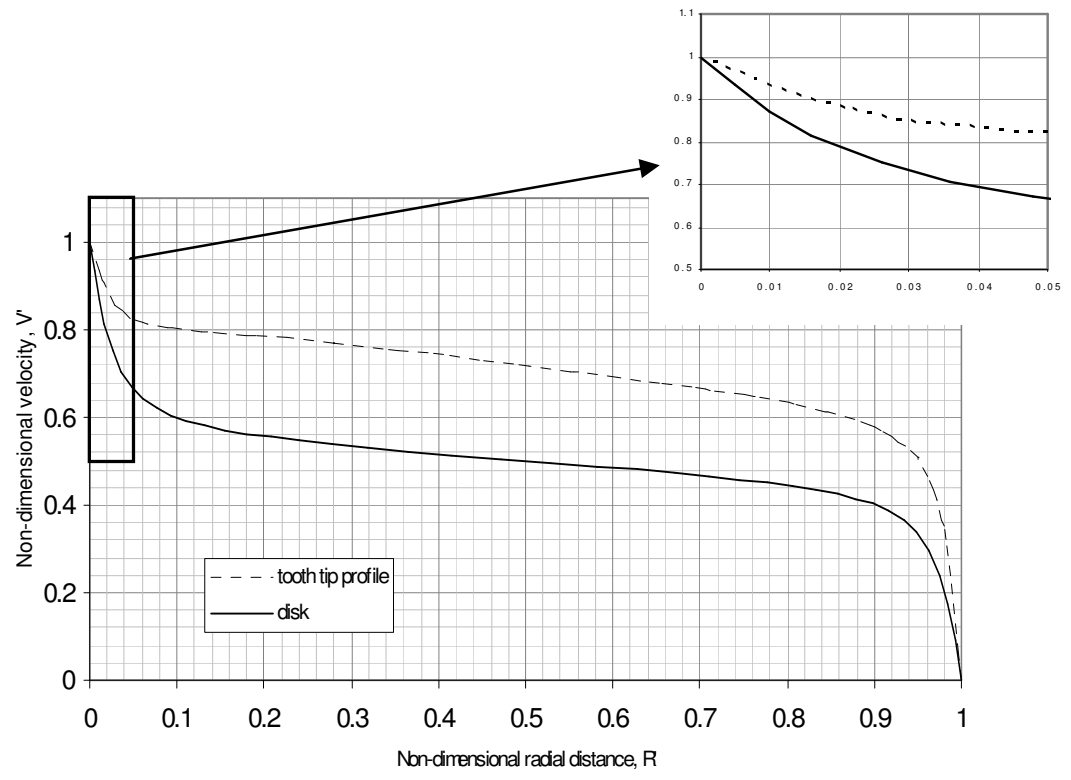

Figure 10: Comparison of azimuthal velocity magnitude profiles across the radial gap between gear or disk and shroud 
For a rotating disk, the most appropriate data in the literature to which the 2D CFD data can be compared is that of Bilgen \& Boulos [19], who developed a correlation for a shaft in an annulus that compared well with their experimental data. Using a gap Reynolds number, $\operatorname{Re}_{g}$ Bilgen \& Boulos found that equation 3, relating Moment Coefficient to geometrical variables and $\mathrm{Re}_{\mathrm{g}}$ was valid for $\mathrm{Re}_{\mathrm{g}}>10^{4}$ (the paper has other correlations for different Re ranges).

$C m=0.065\left\{\frac{r_{o}-r_{i}}{r_{i}}\right\}^{0.3} \operatorname{Re}_{g}^{-0.2}$

In Table 1, for a shaft speed of 20,000 rpm the viscous WPL values obtained for both gear and disk using CFD are compared to the value obtained for a disk using the Bilgen \& Boulos correlation. For the gear modelled, at the outer radius, there are teeth present over approximately $24 \%$ of the "surface".

\begin{tabular}{|l|l|l|}
\hline & Viscous WPL, whole disk & Viscous WPL (24\% of disk) \\
\hline Disk, CFD & $264.7 \mathrm{~W}$ & $63.5 \mathrm{~W}$ \\
\hline Disk, Bilgen \& Boulos & $173.6 \mathrm{~W}$ & $41.7 \mathrm{~W}$ \\
\hline Gear, CFD & & $32.6 \mathrm{~W}$ \\
\hline
\end{tabular}

Table 1: Comparing viscous losses for gear and disk

For the configuration examined, taking the appropriate fraction of the disk WPL does yield a figure of the right order of magnitude as the gear viscous WPL, but significantly over estimates. As Figure 6 illustrates, the viscous losses are considerably smaller than the pressure losses in any case and so for an approximate calculation this may be a useful approach to estimating viscous losses for a gear. However, further work would be required to verify the range of applicability and it would not be a suitable approach for detailed design calculations.

\subsection{Effect of peripheral shroud clearance}

Although this paper only reports $2 \mathrm{D}$ single phase data, it is nevertheless interesting to look at the effect of peripheral shroud clearance on WPL to establish whether there is an optimum clearance. Computationally five peripheral shroud clearances have been investigated: 1, 2.5, 
5, 7.5 and $10 \mathrm{~mm}$. Experimental data exists for three of these, namely $1 \mathrm{~mm}, 5 \mathrm{~mm}$ and $10 \mathrm{~mm}$ (Lord [2]). Comparison of computed and experimental data for a $1 \mathrm{~mm}$ peripheral shroud clearance is shown in Figure 5, with comparisons for $5 \mathrm{~mm}$ and $10 \mathrm{~mm}$ peripheral shroud clearances shown in Figure 11. In these figures the line for total WPL includes the sides losses (taken from the Townsend [7] correlation) while the "CFD" line includes only edge losses. As Figure 10 shows, the 2D CFD under-predicts the WPL at larger shroud clearances, particularly at higher shaft speeds.

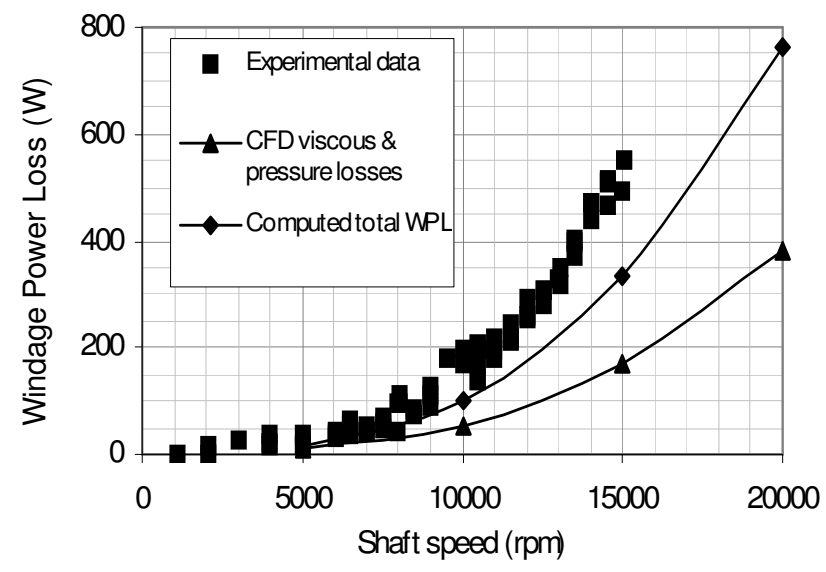

a) $5 \mathrm{~mm}$ peripheral clearance $(g / D=0.025)$

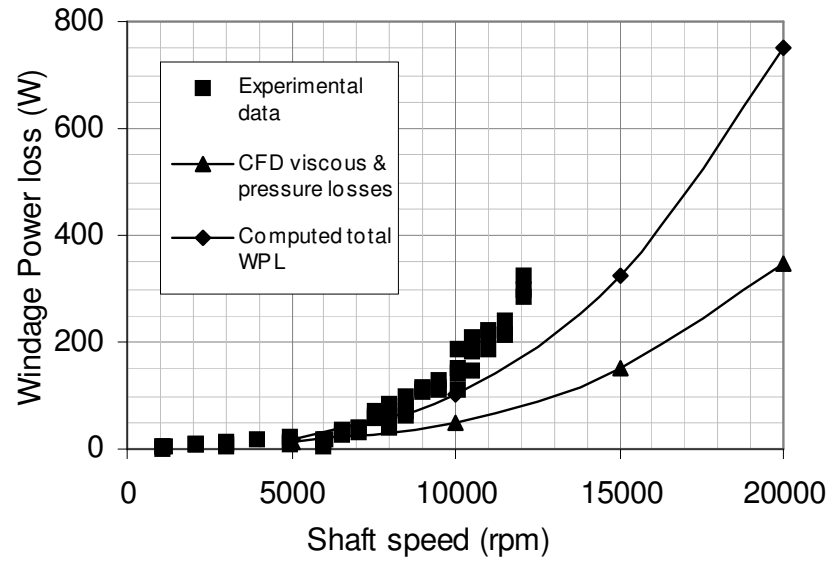

b) $10 \mathrm{~mm}$ peripheral clearance $(g / D=0.05)$

Figure 11: Comparison of experimental and CFD data.

Figure 12 shows the variation in WPL with shroud clearance and compares computed values to experimental data. The experimental data is quite sparse, and for the 2D model applied the match to experimental data is reasonably good, particularly at the larger shroud spacings. However, a significant difference is that the experimental data shows lower WPL for the $5 \mathrm{~mm}$ shroud compared to the $1 \mathrm{~mm}$ shroud whereas the experimental data does not. This may be due to experimental uncertainty or may indicate that perhaps the $2 \mathrm{D}$ model is not able to capture all the significant flow features and that a full 3D model is required. It is interesting to note that for both bevel gear and disk Lord's experimental data shows a minimum WPL although it does not for the spur gear. 


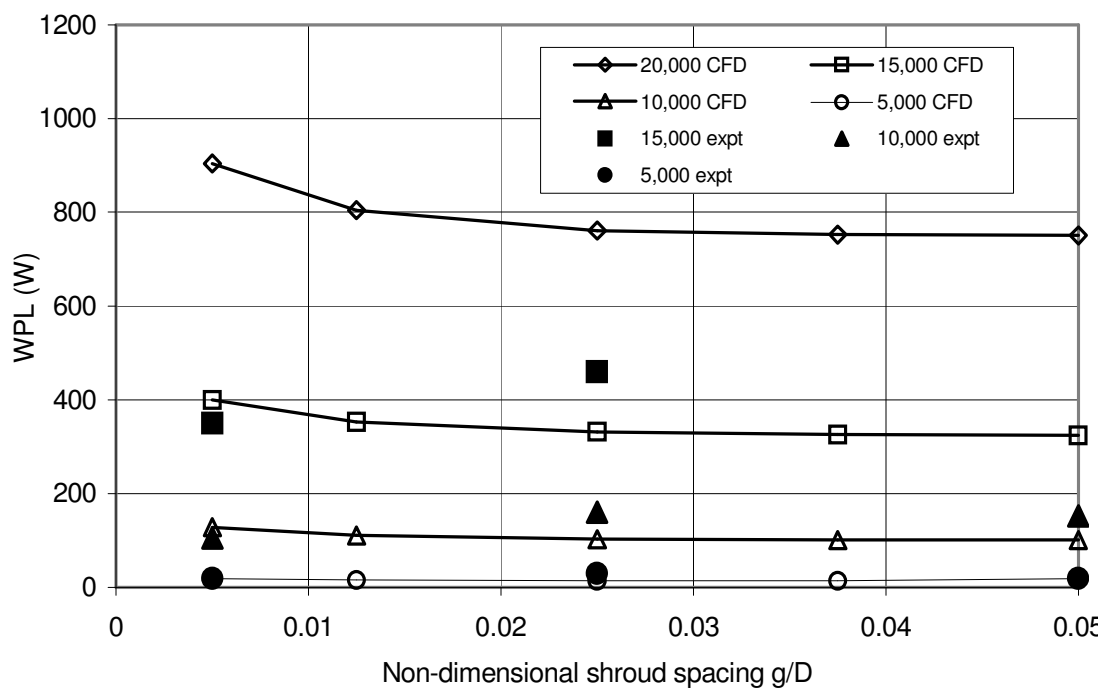

Figure 12: Variation in WPL with peripheral shroud spacing at a number of shaft speeds, showing experimental and computational data

\subsection{Effect of gear tip geometry}

The sharp edges in a machined gear geometry cause handling difficulties and reduce wear resistance. Dawson [4] found that a $5^{\circ}$ chamfer on half the tooth tip, known to improve material handling and extend wear life also led to reduced WPL. Examination of pressure contours in the gear tooth cavity shows where the static pressure is highest and suggests the region for potential modification as illustrated in Figure 8. In this section results are presented comparing chamfered, filleted and sharp tooth forms for the tooth form used by Lord [2]. Unfortunately, no experimental data is available for comparison. Two chamfers are investigated: the first has a $0.1 \mathrm{~mm}$ by $45^{\circ}$ chamfer and the second a $0.25 \mathrm{~mm}$ by $45^{\circ}$ chamfer. In addition, two fillet radii are considered, $0.1 \mathrm{~mm}$ and $0.25 \mathrm{~mm}$. As the tooth height is $2.3 \mathrm{~mm}$ these correspond to $4.3 \%$ and $10.9 \%$ of the tooth height.

Figure 13 shows results for WPL for an unchamfered gear and the chamfered/filleted cases. In each case the shaft speed was 20,000 rpm and the peripheral shroud spacing $5 \mathrm{~mm}$. The data shows that both viscous and pressure losses are affected by the gear tip modifications, but as the viscous losses are small compared to pressure losses the main effect is the change of pressure distribution within the tooth cavity. Overall, a small or moderate chamfer gave a 
reduction in the sum of viscous and pressure losses (approximately $12 \%$ in both cases) whereas a small fillet increased these losses by $13 \%$ and a moderate fillet gave no improvement over the sharp-edged case. Although not conclusive or validated, this research suggests, in line with Dawson's previous study, that a small chamfer on the gear tip corner would reduce WPL.

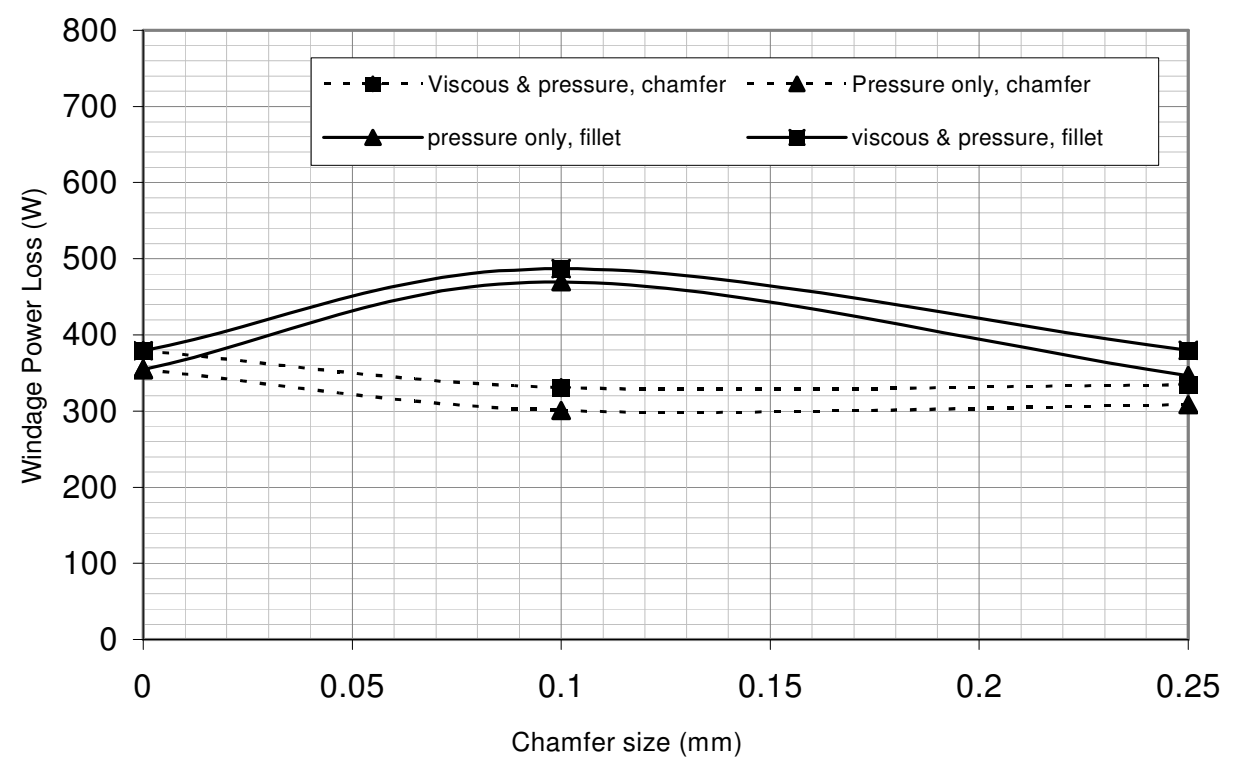

Figure 13: Influence of chamfer size on computed WPL for the $5 \mathrm{~mm}$ peripheral shroud $(\mathrm{g} / \mathrm{D}$ $=0.025$ ) at 20,000 rpm using the RSM turbulence model.

The pressure distribution along a gear tooth for the sharp-edge and chamfered cases is depicted in Figure 14. Modification of the gear tip geometry reduces both the maximum pressure found on the leading corner of the gear tooth and the pressure along the trailing gear tooth face. These are opposing effects in that there would be no retarding force on the gear if leading and trailing faces had the same pressure distribution. However, the net effect is an overall reduction in retarding force when the leading edge is chamfered. The $45^{\circ}$ chamfers investigated did not give the same reduction in losses as Dawson's $5^{\circ}$ chamfer and there is clearly room for further investigation in this area. It would also be interesting to investigate wear patterns on gear teeth since this study suggests that a small amount of rounding on the leading gear tip edge could significantly increase windage losses. 


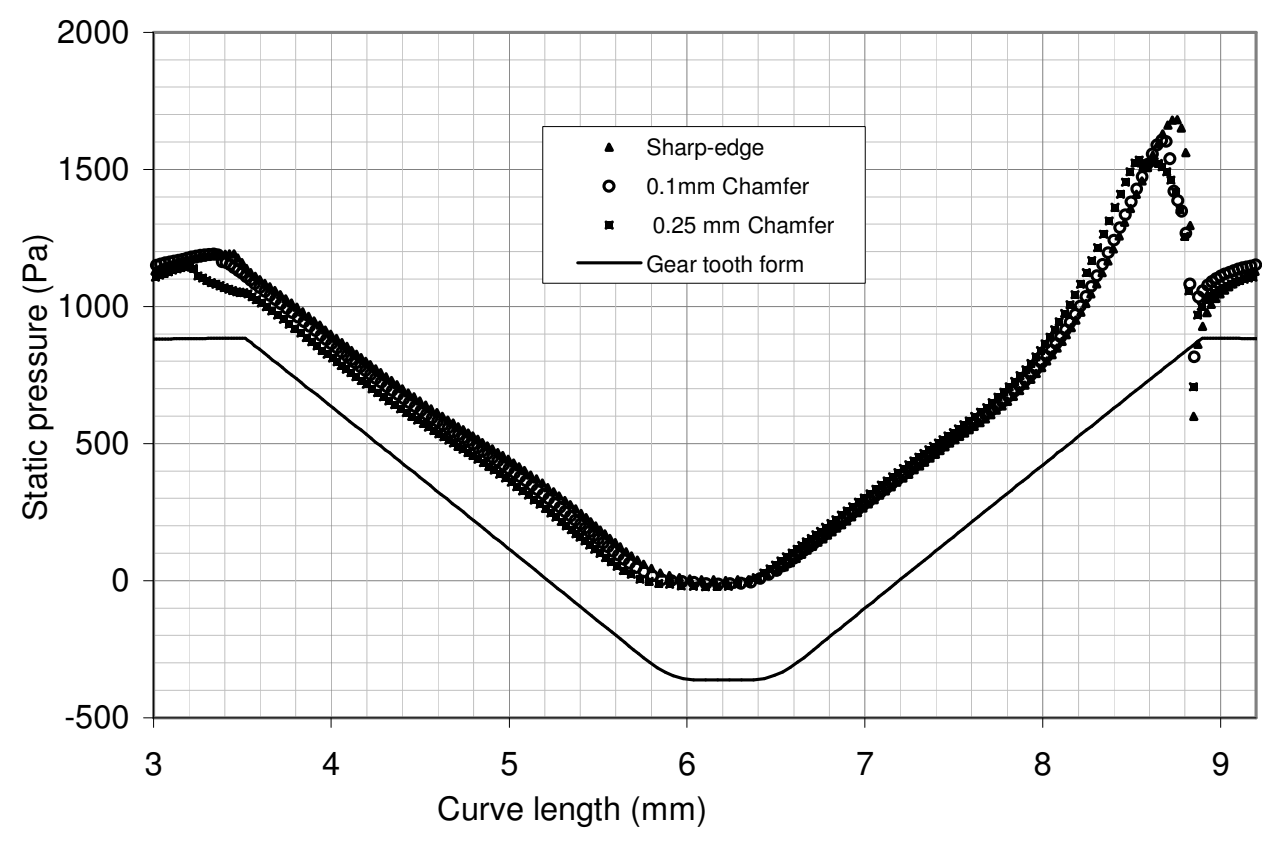

Figure 14: Effect on cavity static pressure distribution of chamfered leading edge.

\section{Conclusion}

Two dimensional computational fluid dynamics (CFD) models of the air flow around a single spur gear have been computed and the data compared with available experimental data. It was found that the results were sensitive to the choice of turbulence model with the RSM model giving the best results. Although reasonable agreement was found with the experimental data, it is noted that the gear side losses are a significant fraction of the total losses and reliance on Townsend's [7] correlation for spur gear losses (as used here due to the $2 \mathrm{D}$ assumption for modelling) may not be appropriate over the parameter range of this study. It is recommended that some $3 \mathrm{D}$ modelling work is conducted to follow up from this work.

A comparison of disk and gear viscous windage power loss showed that it is not possible to predict viscous losses for the spur gear studied by simply taking the appropriate fraction of disk losses. This is because the core velocity is greater in the case of the gear and consequently the velocity gradient predicted at the rotating surfaces for the disk is much 
steeper. As viscous losses are proportional to the velocity gradient, this difference is significant.

An investigation into the effect on windage power loss of peripheral shroud spacing found that there was no clear optimum spacing. Initially WPL reduces with increased spacing, with the curve flattening at larger shroud spacings negating the benefit of further increase. A spacing of $1 \mathrm{~mm}$ produced the highest WPL prediction, so close fitting shrouds cannot be recommended from the predictions. However, this contradicts that data of Lord where there was a small benefit in a close fitting shroud compared to the larger spacings. This suggests the need for a full 3D study.

As WPL is dominated by the pressure loss a limited study into the effect of modifying the gear tooth tip geometry was conducted. This showed that there was benefit in chamfering the corner, although a small fillet radius adversely affected the WPL. This study has not examined the effect on other transmission losses if the gear tooth profile is modified. However, it is clear that significant gear tooth wear could lead to increased losses.

Using CFD to investigate gear windage power loss has shown promising results within this study. It is clear that the investigation needs to be extended to look at the effects of the gear sides by running a fully three dimensional calculation. In addition, this study has been single phase only and there is clearly scope for two-phase modelling to be carried out as the oil will be a significant factor in determining WPL for transmission systems. The inclusion of the meshing gear also presents significant challenge for future CFD modelling of such systems.

\section{Nomenclature}

\section{Symbol Definition}

D Gear outer diameter

g Distance between rotating element and shroud

$h \quad$ Thickness of disk or gear edge

$k \quad$ Turbulent kinetic energy
$\underline{\text { Unit }}$
$\mathrm{m}$
$\mathrm{m}$
$\mathrm{m}$
$\mathrm{m}^{2} \mathrm{~s}^{-2}$ 


\begin{tabular}{|c|c|c|}
\hline$N$ & Shaft speed in revolutions per minute & $\mathrm{rev} / \mathrm{minute}$ \\
\hline$P$ & Windage power loss & W \\
\hline$P_{\text {sides }}$ & Windage power loss from sides & W \\
\hline$r$ & radial distance from gear centre & $\mathrm{m}$ \\
\hline$r_{c}$ & Radius or chamfer size of the gear tip & $\mathrm{m}$ \\
\hline$r_{i}$ & Radius of inner annulus (disk) & $\mathrm{m}$ \\
\hline$r_{0}$ & Radius of outer annulus (wall) & $\mathrm{m}$ \\
\hline$r_{g o}$ & Outer radius of gear & $\mathrm{m}$ \\
\hline$R^{\prime}$ & Non-dimensional radial distance $R^{\prime}=\frac{r-r_{g o}}{r_{o}-r_{g o}}$ & - \\
\hline$T$ & Torque & $\mathrm{Nm}$ \\
\hline$v_{\theta}$ & azimuthal velocity & $\mathrm{ms}^{-1}$ \\
\hline $\mathrm{V}^{\prime}$ & Non-dimensional azimuthal velocity $V^{\prime}=\frac{60 v_{\theta}}{2 \pi N r_{g o}}$ & \\
\hline$\varepsilon$ & Turbulent dissipation rate & $m^{2} s^{-3}$ \\
\hline$\rho$ & Density & $\mathrm{kg} / \mathrm{m}^{3}$ \\
\hline$\mu$ & Viscosity & $\mathrm{kgm}^{-1} \mathrm{~s}^{-1}$ \\
\hline$\omega$ & Angular velocity & $\operatorname{rad} \mathrm{s}^{-1}$ \\
\hline $\mathrm{Cm}$ & Moment coefficient, $C m=\frac{T}{0.5 \pi \rho \omega^{2} r_{i}^{4} h}$ & - \\
\hline $\operatorname{Re}_{\text {rot }}$ & Rotating Reynolds Number, $\operatorname{Re}_{r o t}=\frac{\rho \omega r_{g o}^{2}}{\mu}$ & - \\
\hline $\operatorname{Re}_{\mathrm{g}}$ & Gap Reynolds number, $\operatorname{Re}_{g}=\frac{\omega r_{i}\left(r_{o}-r_{i}\right)}{v}$ & - \\
\hline
\end{tabular}

\section{References}

1. Weiss, T., Hirt, M., 2002, "Efficiency Improvements for high speed gears", International Conference on Gears, Munich, Germany, VDI, 2. pp. 1161-1174 
2. Lord A.A., 1998, "An experimental investigation of Geometric and Oil Flow Effects on Gear Windage and Meshing losses", PhD Thesis, University of Wales, Swansea

3. Dawson, P. H., 1984, "Windage loss in larger high-speed gears" Proceedings of the Institution of Mechanical Engineers, 198A, 1, pp. 51-59

4. Dawson, P. H., 1988, "High speed gear windage". GEC Review, 4, No. 3

5. Winfree, D. D., 2000, "Reducing gear windage losses from high speed gears", Proc. DETC'00, ASME Power transmission and gearing conference, Sep. 10-13, Baltimore Maryland., pp. 747-756

6. Barnes, J.P., 1997, "Non-Dimensional Characterization of Gear Geometry, Mesh Loss and Windage", Fall AGMA/ASME meeting, 97FTM11, 12p

7. Townsend, D.P., 1991, "Dudley's Gear Handbook", $2^{\text {nd }}$ Edition, McGraw-Hill, NY, USA, Section 12.5 .2

8. Dudley, D.W, 1962, "Gear Handbook, The Design, Manufacture and Application of Gears", McGraw-Hill, (pp. 14-20 to 14-21)

9. Heingartner, P.; Mba, D.; 2003, "Determining power losses in the helical gear mesh; case study", DETC'03, ASME 2003 Design Engineering Technical Conferences and Computers and Information in Engineering Conference, 4B, pp. 965-970

10. Anderson, N.E., Loewenthal, S.H., 1986, "Efficiency of non-standard and high contact ratio involute spur gears," Journal of Mechanisms, Transmissions and Automation in design, March, 108, pp. 118-126.

11. Handschuh, R.F.; Kilmain, C.J., 2003, "Preliminary comparison of experimental and analytical efficiency results of high-speed helical gear trains", DETC'03, ASME 2003 Design Engineering Technical Conferences and Computers and Information in Engineering Conference, 4B, pp. 949-955

12. Diab, Y.; Ville, F.; Changenet, C.; Velex, P., 2003, "Windage losses in high speed gears - preliminary experimental and theoretical results", DETC'03, ASME 2003 Design Engineering Technical Conferences and Computers and Information in Engineering Conference, 4B, pp. 941-947 
13. Diab, Y.; Ville, F.; Velex, P., Wendling, M., 2005, "Simulations and Experimental Investigations on Windage Losses in High-Speed Gears", VDI-Berichte Nr. 1904, pp 14351450

14. Lee, C W, 2004, "Air and Oil Flow Investigations in an Aeroengine Bearing Chamber", University of Nottingham PhD thesis, chapter 6.

15. Launder B.E. and D. B. Spalding, 1972, "Lectures in Mathematical Models of Turbulence", Academic Press, London, England,

16. Choudhury D., 1993, "Introduction to the Renormalization Group Method and Turbulence Modeling", Fluent Inc. Technical Memorandum TM-107, 1993.

17. Launder, Reece, and Rodi, 1975, "Progress in the Development of a Reynolds-Stress Turbulence Closure", Journal of Fluid Mechanics, vol. 68 pp537-566

18. Kader B, 1993, "Temperature and Concentration Profiles in Fully Turbulent Boundary Layers", Int. J. Heat Mass Transfer, 24(9):1541-1544.

19. Bilgen E. and Boulos R., 1973, "Functional dependence of torque coefficient of coaxial cylinder on gap width and Reynolds number", Journal of Fluids Engineering, Vol. 1 pp 122126. 